\title{
Didier Coureau (dir.), Un cinéma de poésie
}

\section{Roberta Sapino}

\section{(2) OpenEdition}

\section{Journals}

\section{Edizione digitale}

URL: http://journals.openedition.org/studifrancesi/1514

DOI: 10.4000/studifrancesi. 1514

ISSN: 2427-5856

\section{Editore}

Rosenberg \& Sellier

\section{Edizione cartacea}

Data di pubblicazione: 1 décembre 2015

Paginazione: 654

ISSN: 0039-2944

\section{Notizia bibliografica digitale}

Roberta Sapino, «Didier Coureau (dir.), Un cinéma de poésie», Studi Francesi [Online], 177 (LIX | III) |

2015, online dal 01 décembre 2015, consultato il 19 janvier 2021. URL: http://

journals.openedition.org/studifrancesi/1514 ; DOI: https://doi.org/10.4000/studifrancesi.1514

Questo documento è stato generato automaticamente il 19 janvier 2021.

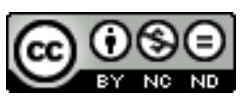

Studi Francesi è distribuita con Licenza Creative Commons Attribuzione - Non commerciale - Non opere derivate 4.0 Internazionale. 


\title{
Didier Coureau (dir.), Un cinéma de poésie
}

\author{
Roberta Sapino
}

\section{NOTIZIA}

DIDIER COUREAU (dir.), Un cinéma de poésie, Grenoble, ELLUG, 2014, Recherches \& Travaux, n. 84 , pp. 220.

1 Con il presente volume Didier COUREAU prosegue un lavoro di ricerca sulle relazioni tra cinema e poesia intrapreso insieme al gruppo di ricerca «Traverses 19-21» dell'Université Stendhal Grenoble Alpes e inaugurato nel 2010 con l'organizzazione delle giornate di studio «Cinéma, Arts vidéo, Poésie: les images au miroir des images». Pur riferendosi al «cinema di poesia» teorizzato da Pasolini, il titolo raccoglie sotto di sé interventi piuttosto eterogenei per forma e contenuto che talvolta debordano dal senso primo della formula pasoliniana affrontando-riassume Coureau nell'agile introduzione (Un cinéma de poésie, interrogations premières, pp. 5-11) - le diverse forme di commistione e influenza tra i due linguaggi, i punti di frattura e gli effetti d'eco, le manifestazioni visuali e verbali di un certo «esprit de poésie» che è innanzitutto uno sguardo sul mondo.

2 La prima sezione, «Le cinéma et les poètes», si apre con il contributo più corposo del volume (Esra AYKIN, "Was it a vision, or a walking dream?". Constellations intérieures, incandescences du sensible: "Bright Star" de Jane Campion ou la nuit étoilée de Keats, pp. 15-53), volto a mettere in luce come la neozelandese Jane Campion riesca a sottrarsi alle convenzioni della biografia d'autore dando vita a un'opera in cui il «regard poétique» di Keats affiora in un accordo intimo, intuitivo, che supera la sfera della citazione. In Des fragments intranquilles: le cinéma d'Oliveira à la lumière de Pessoa (pp. 55-69), Guillaume Bourgors dapprima smentisce l'idea che l'opera di Pessoa sia totalmente estranea all'ambito cinematografico, per poi mostrare come la sua estetica trovi un prolungamento nei film di Oliveira, in cui il gioco sulla moltiplicazione delle 
identità testuali e il costante dialogo tra mito e realtà contribuiscono a fare del cinema, come della poesia, «un art du rapport».

Intitolato Cinéma poétique, poétique du cinéma, il secondo capitolo si interroga sulle modalità con cui il linguaggio filmico, rielaborato dall'interno, si confronta con le proprie frontiere per generare nuove forme poetiche. Il contributo di Thomas de DAVYDOFF (Le «parti pris des choses»: Ozu et la poésie "Au contraire d'une fonction de numéraire facile et représentatif", pp. 73-87) mostra come la consapevolezza dell'insufficienza del linguaggio comune si concretizzi nei film di Ozu non sotto forma di silenzio, bensì come ricerca di una lingua nuova, poetica, fatta di spazi vuoti e tempi sospesi, metonimie e immagini evanescenti, e in cui allo sguardo dell'uomo sull'altro si affianca quello, maestoso e temibile nella sua immobilità, delle cose sulle futilità umane. Olivier SALAZAR-FERRER si sofferma su Maya Deren et la transfiguration filmique du temps (pp. 89-106), leggendo nell'opera teorica e filmica dell'artista una manifestazione del "poétique» inteso come tensione tra una funzione disorganizzatrice, che scardina il linguaggio codificato, e una funzione creatrice, che elabora forme nuove in grado di agire sullo spettatore attraverso l'emozione. In chiusura, Didier COUREAU (“Correspondances" d'Eugène Green. La poésie probablement, pp.107-124) guarda a Correspondances di Green come a un "poème filmique», un'opera poetica fondata sulla visione e nutrita dall'intreccio di diverse corrispondenze: epistolari, ma anche - in senso baudelairiano - corrispondenze tra oggetti, materie, parole, immagini, arti.

La terza sezione inverte la prospettiva articolandosi intorno alle possibilità di generare «Une poésie cinématographique». In Kinoptique du ciel d'encre (pp. 127-142) Christophe WALL-ROMANA propone l'idea che la poesia moderna sia caratterizzata da una ricerca di resa letteraria della visione in movimento e del movimento, che egli osserva concentrandosi sull'opera di Mallarmé e Valéry e in particolare sulle immagini dell'universo astronomico e del volo degli uccelli, luoghi privilegiati per la sperimentazione di una «nouvelle écriture mobile». Catherine soulier (Une poésie 'sous influence'? (Ou quand la poésie fait son cinéma), pp. 143-157) propone poi di riconsiderare le definizioni di "cinélittérature», "cinégraphie» e "cinéfiction», modificandole ove necessario, per render conto della complessità di operazioni come Une histoire passera ici di Ariane Dreyfus e Flip-Book di Jérôme Game, in cui l'influenza del cinema contribuisce a ridefinire la nozione di poesia attraverso il confronto con un'alterità capace di scardinare i clichés idealizzanti ed estetizzanti ancora spesso legati al genere.

All'impronta accademica della prima parte del volume fa da contrappunto il capitolo conclusivo Poète spectateur, poète filmeur, cinéaste poète, in cui la creazione artistica accoglie e guida il discorso critico: Jacques LAURANS (Le marcheur et son ombre, pp.161-165) propone una visione-narrazione di Le Marcheur, film documentario in forma di autoportrait di Jean-Noël Christiani, Gérard LEBLANC (Viecinéma, pp.167-182) riflette sulla propria pratica video-filmica ripercorrendo poeticamente una relazione amorosa, mentre Frank SMITH (Poésie hors-champ: "Eureka", pp. 183-200) condivide il testo del suo film Eureka facendolo precedere da un'introduzione critica in forma di abbecedario, un'analisi del proprio lavoro in cui le diverse voci emergono "comme autant de forces en devenir». Chiude il volume un contributo composito ("Asientos" (1995) de François L. Woukoache, pp. 201-213), nel quale il testo delle voci fuori campo di Asientos, ad opera di François L. WOUKOACHE e Claire JAUMAIN, è preceduto da un'introduzione a cura di Didier Coureau e da un Texte de présentation dello stesso Woukoache, e seguito poi da una poesia di Coureau intitolata Temps tissage (Asientos). 
6 Muovendosi agilmente in un'area geografica e culturale di notevole estensione (dall'Inghilterra al Portogallo al Giappone agli Stati Uniti all'Africa), il volume segue piste relativamente poco battute, propone nuove strade, rileva connessioni tra mondi artistici anche lontani, proseguendo con cura un lavoro di ricerca che, afferma Coureau, è destinato a estendersi in pubblicazioni future. 